\title{
Governo e Comunicação
}

\section{ARCHIBALDO DESLANDES FIGUEIRA}

\author{
Jornalista profissional; ex-integrante da \\ Assessoria de Imprensa do Ministério do \\ Planejamento e Coordenação Geral
}

"Ả medida em que as nações passam dos padrões da soprodade tradicional para os da sociedade moderna e industrial, processa-se uma espetacular evolução nas suas comunicações. Esta evolução é provocada pela evolução econômica, social e politica que integra o crescimento nacional.

Os países que têm pressa não se podem dar ao luxo de uma massa vagarosa. Exigem a cooperação ativa e informada dos cidadãos das aldeias, assim como das cidades. Seus recursos humanos são indispensáveis. Eles vão ter, portanto, de acelerar o fluxo de informação, dar educação onde ela nunca existiu antes, alfabetizar e proporcionar ensino técnico em bases muito amplas. E a única maneira de fazê-lo e de cumprir o calendário previsto é utilizar todos os recursos da comunicação moderna. Um dos problemas da administração consiste em adaptar, em conjunto, as peças em transformação o mais eficientemente possível. Matéria-prima, máquinas e trabalhadores devem achar-se preparados na ocasião, mas não muito antes que as fábricas estejam prontas. O povo deve aprender a ler e ir à escola, mas somente quando houver oportunidade de fazer uso produtivo de suas novas habilidades.

rápido essência do desenvolvimento econômico é o aumento épido da produtividade econômica da sociedade. Produtividade in chave. E o setor mais produtivo da sociedade moderna é o industrial. Mas um país em desenvolvimento não se pode dar ao luxo de aplicar toda a sua renda de investimentos na indústria, por mais produtiva que ela seja. Desta forma, a agricultura deve também ser modernizada, para que menos agricultores posSam cultivar mais alimentos e uma parte da população agrícola possa ser liberada para trabalhar na indústria". (Wilbur Schramm). 


\section{O desempenho econômico brasileiro}

Ao comemorar o Brasil o décimo aniversário da Revolução de março de 64 , o nosso desenvolvimento já não mais será apelidado, nem internamente e nem no exterior, de "milagre". Afirial de contas, só nos últimos quatro anos o Produto Interno Bruto cresceu de cerca de $41 \%$; a população, de $12 \%$; o consumo global, de $36 \%$; a população economicamente ativa passou de 29 para 32 milhões; o consumo de energia elétrica registrou um incremento de $58 \%$; a rede rodoviária federal pavimentada, de $62 \%$; o sistema postal, de $233 \%$; o sistema nacional de telex, de $234 \%$; o sistema nacional de telecomunicações, de $49 \%$, e a tonelagem da frota mercante, de $63 \%$. Vinte e dois milhões de crianças devem estar cursando o primeiro grau. Dois milhões $e$ 200 mil, matriculados no segundo grau e 820 mil nas faculdades. E O MOBRAL alfabetizou 6,5 milhões de brasileiros entre $15 \mathrm{e}$ 35 anos.

E mais : como marco, vale lembrar que já em 1972 a indústria nacional estava produzindo 610 mil veículos automotores, 1,1 milhão de televisores, 4,1 milhões de fonógrafós e radiofonógrafos e 2,2 milhões de rádios transistorizados.

Para que se tenha uma noção exata do progresso que vem sendo realizado, em termos econômicos, nada melhor do que um exame da obra "Brasil 2.002", de Mário Henrique Simonsen, analisando o desempenho da economia brasileira de 1920 aos dias atuais, "e a partir de 1920" - diz ele — "ante a insuficiência de séries estatísticas dignas de confiança com relação aos períodos anteriores".

- Em 1920 - diz o autor - a população brasileira era pouco superior a 27 milhões de habitantes. Em moeda de poder aquisitivo de 1965, a renda per capita devia ser da ordem dos 130 dólares anuais, talvez com menores desigualdades regionais do que hoje, mas certamente com acentuadas diferenças pessoais. (...) No decênio de 1920, o produto real cresceu, em média, de $3,7 \%$ ao ano. A agricultura, a indústria e o comércio se expandiram praticamente à mesma taxa média. Embora entre $1920 e$ 30 a potência elétrica instalada quase tenha duplicado, e as primeiras iniciativas tenham surgido na siderurgia e na produção do cimento, não houve mudança substancial na estrutura econômica do País. (...) Bem mais satisfatório parece ter sido o desempenho da economia brasileira no decênio de 1930, particularmente quando se tem em conta as condições mundiais de cri- 
se. (...) Um novo impulso de industrialização iria ser provocado pela Segunda Guerra Mundial, (que) terminada, a primeira preocupação do Governo parece ter sido de desafogar a demanda de importações. (...) Entre 1947 e 1956, dentro dessa política de desenvolvimento liderada pela industrialização substitutiva de importações, o produto real cresceu de $6,4 \%$ ao ano, em média. (...) O Governo Kubitschek marcou o início de um processo ainda mais eufórico de crescimento. O desenvolvimento transformou-se em bandeira política, incentivando-se a industrialização a qualquer custo, escudada em fortíssima proteção aduaneira e em polpudos subsídios cambiais, e promovendo-se uma grande série de obras públicas de vasto impacto publicitário. (Mas) ao terminar o seu mandato, em princípio de 1961, o Governo Kubitschek deixava uma herança difficil de inflação reprimida e de problemas no balanço de pagamentos. Os seus sucessores a complicaram ainda mais. Em seu período meteórico, o Governo Jânio Quadros tentou restabelecer o realismo combial e a representatividade do sistema de preços, mas a falta de medidas complementares serviu apenas para transformar em aberta uma inflação que antes vinha comprimida. O Governo Goulart institucionalizou entre nós a análise antieconômica, com o fortalecimento da inflação, com o endividamento externo desordenado, com a excitação das greves e da subversão, com o apavoramento dos investidores nacionais e estrangeiros diante das incessantes ameaças de confisco. Assim, as taxas de crescimento do produto real cairam, naturalmente, de 10,3\% em 1961 para 5,3\% em 1962 e $1,5 \%$ em 1963 (ano em que ao caos político se superpuseram más safras agrícolas).

Logo após a Revolução de março de 1964, o Governo Castelo Branco iniciou uma etapa heróica de restauração econômica do País, visando ao combate à inflação, ao reequilíbrio do balanço de pagamentos, e à criação de bases para um desenvolvimento sustentável a longo prazo. (...) Em média, no período de $1964 / 67$, o produto real brasileiro expandiu-se de apenas $3,7 \%$ ao ano.

(Mas) desde 1968 o produto real brasileiro vem crescendo a taxas excepcionais, sem precedentes em nossa História : 9,3\% em 1968, 9,0\% em 1969, 9,5\% em 1970, 11,3\% em 1971, com excelentes perspectivas para 1972. Muitos observadores internacionais, diante dessas cifras, passaram a referir-se à ocorrência de um "milagre brasileiro". Expressão bastante imprópria, segundo o Ministro Delfim Neto, pois afinal o milagre é o efeito sem causa. Enquanto que o nosso crescimento recente pode ser tudo, 
menos o fruto da geração espontânea. Na realidade, trata-se de uma boa demonstração de que a teoria econômica funciona na prática".

\section{A evolução das comunicações}

Destacados os principais indicadores da evolução da economia brasileira, resta-nos examinar até onde este progresso implicou naquela "notável evolução das comunicações" referida por Schramm.

Do ponto de vistas dos meios eletrônicos de massa e da comunicação individual, a resposta é positiva. Mas, do ponto de vista do processo, do fluxo dinâmico da comunicação, ou seja, de intercâmbio - e é bom frisar, nos dois sentidos - de informações entre governantes e governados, que promove a participação de todos no esforço para o desenvolvimento, poderíamos considerar-nos bem aquém do estágio que conseguimos atingir em termos de desenvolvimento econômico. Como, por exemplo, se pode explicar o quadro abaixo, quando se leva em conta que mais brasileiros adultos aprenderam a ler e a escrever e mais crianças e jovens foram matriculados na escola?

\section{Consumo Aparente de Papel (mil ton.)}

Anos

1967

1968

1969

1970

1971
Todos os Tipos

968,7
$1.081,1$
$1.119,3$
$1.320,3$
$1.511,5$

Papel de Imprensa

187,1

235,0

232,0

251,8

269,7

O quadro, extraído do Anuário Estatístico do Brasil, denuncia não apenas ter havido uma queda no consumo de papel de imprensa no ano de 1969, como o fato de este consumo estar aumentando a uma taxa estacionária de 1970 para cá.

Redução das tiragens, do número de leitores, ou da quantidade de jornais? - argüi-se ante a frieza dos números. Concorrência do rádio ou da televisão?

Comecemos por eliminar o último argumento. Se examinarmos a estrutura da programação das 1.008 estações de rádio existentes no País, fazendo uma média de 13 horas de emissões 
diárias, verificaremos que os programas informativos e educatiVos (incluindo a "Voz do Brasil") só ocupam 2 horas e 40 minutos. As 52 emissoras de TV existentes, nas 11 horas diárias que transmitem, em média, só dedicam aos informativos e à educação 144 minutos. Quer dizer : tanto o rádio como a TV, no Brasil, estão mais voltados para o entretenimento que para a difusão de novos conhecimentos, não competindo, portanto com os jornais.

De outra parte, se compararmos o número de jornais e demais periódicos existentes em anos sucessivos, verificaremos estar havendo o desaparecimento do pequeno jornal da cidade e do interior, enquanto crescem uns poucos representantes da chamada "grande imprensa". E se considerarmos a relação população/jornais diários, verificaremos em 1964, quando havia $80 \mathrm{mi}-$ lhões de brasileiros, apenas três milhões adquiriam diariamente um jornal. Em 1971, embora a população se aproximasse dos 100 milhões, o número de leitores diários de uma folha não chegava a três milhões e cem mil.

Estas considerações só nos conduzem a uma conclusão ficica : os meios de massa não estão encontrando material suficiente para o cumprimento de sua missão de informar. E, se considerarmos as características do nosso Estado, concluiremos também que o Governo, em todos os seus níveis, constitui a principal fonte de informação. Se ela falta, é porque há algo de errado com o Sistema Governamental de Comunicação.

tada As falhas do Sistema, aliás, vêm de há muito sendo aponrio por Alberto Dines, Luis Carlos Oliveira, Eduardo Pinto, Mátício Franklin e João Batista de Freitas, entre outros, em artigos para os Cadernos de Jornalismo e Comunicação, bem como por Alan Viggiano e José Augusto Guerra, pela Revista do Serviço Público e, mais recentemente, Carlos Chagas e Carlos Castello Branco em conferências e artigos de jornal.

do No entanto, para não corrermos o risco de estarmos senexcessivamente críticos, devemos ressalvar que, afora o pesadelo do Departamento de Imprensa e Propaganda (30-12-39$25-5-45$ ), somente a partir de 15 de janeiro de 1968, com a criafão da Assessoria Especial de Relações Públicas da Presidência da República, AERP, começou o Brasil a constituir um Sistema Governamental de Comunicação, congregando as Assessorias de Imprensa ou Coordenações de Relações Públicas de todos os órgãos da Administração Federal, Direta e Indireta. 
Já em setembro do ano de sua criação, a AERP, promovendo o I Seminário de Relações Públicas do Executivo, sob a presidência do Ministro do Planejamento e Coordenação Geral, Hélio Beltrão, conseguiu identificar muitos dos entraves ao fluxo de comunicação entre governantes e governados :

* Considerou "imperativa" a reorganização do programa radiofônico "A Voz do Brasil", bem como a reformulação das publicações oficiais;

* Anotou a necessidade de o Governo fixar uma filosofia de comunicação;

* Recomendou a promoção de reuniões trimestrais dos serviços de Relações Públicas dos órgãos da Administraçäo Federal, mediante convocação da AERP, "para que exista perfeita sinergia entre todos, que trabalharão no sentido da criação de uma imagem correta das realizações governamentais;

* Assinalou a necessidade de reequipar tanto de recursos humanos como materiais, a Agência Nacional, à qual seria atribuída a tarefa de distribuição de todo o noticiário governamental, cuja redação deveria caber a profissionais de imprensa encarregados da direção dos setores de divulgação de cada órgão. Recomendou-se também que "os serviços de Relações Públicas" prepararão a opinião pública quando o Executivo estiver na iminência de adotar medidas de grande repercussão, notadamente as que forem ensejar o aparecimento de áreas de atrito ou de pressão".

O Seminário procurou também levantar a situação dos órgãos públicos com referência aos serviços regulares de Relações Públicas, comprovando a existência de "um enorme desconhecimento em torno do papel exercido pelas Relações Públicas, agra vado pelo pequeno número de profissionais existentes no País no exercício da profissão em caráter regular e contínuo". Cons tatou, ainda, a inadequação do material informativo fornecido pe los Ministérios, bem como a inexistência de verbas específicas para os setores correspondentes, o desaparelhamento das estações de rádio e de televisão oficiais, conflito de remuneração a preços de mercado dos profissionais frente aos niveis do funcio nalismo público, e, mais grave, denunciou :

"Em certos casos, os serviços de Relações Públicas exis" tentes em alguns órgãos subordinados estão melhor estruturados e contam com maiores recursos do que o próprio serviço de RP do Gabinete do Ministro, ocorrendo também que a promoção das 
atividades dos órgãos subordinados é feita em seu benefício exclusivo, desvinculados da promoção do plano global do Governo, assim como a omissão do nome do Governo Federal em atividades dos Estados e Municípios, embora havendo uma participação efetiva dele."

E destacou que, de modo geral, os órgãos do Governo não utilizavam a técnica de pesquisa de opinião para fundamentar e/ou corrigir distorções referentes a atos ou medidas oficiais de reperCussão pública, para o que recomendou a elaboração de um plano de Relações Públicas semestral ou anual, com base no Programa Estratégico de Desenvolvimento e a implantação de um sistema de análise de notícias para o pronto esclarecimento dos fatos.

Pouco depois do encerramento do Seminário, entretanto, verificou-se a crise política que determinou o Ato Institucional n. ${ }^{\circ}$ 5 e, logo em seguida, a morte do Presidente Costa e Silva.

\section{A mobilização dos recursos humanos}

Com a posse, no Governo, do Presidente Emílio Médici, notou-se uma verdadeira mudança de estilo no trabalho da AERP, já que a preocupação do novo Chefe de Estado era menos com a imagem do Governo do que para a mobilização de todos para o esforço em busca do desenvolvimento.

"O meu Governo - afirmara o General Emílio Médici, ao Ser indicado para a Presidência - "vai iniciar-se numa hora difícil. No seu curso, jamais procurarei impor o meu programa administrativo mediante efeitos de propaganda ou a simples divulgação de resultados estatísticos. O desenvolvimento econômico não poderá ser obra exclusiva da administração pública, e sim uma tarefa global da Nação, exigindo a colaboração dos brasileiros de todas as classes e regiões. Democracia e desenvolvimento não se resumem em iniciativas governamentais : são frutos da vontade coletiva que cabe ao Governo coordenar e transformar em autênticos e efetivos objetivos nacionais. Espero que cada brasileiro faça justiça aos meus sinceros propósitos de servi-lo. $E$, confesso, lealmente, que gostaria de que o meu Governo viesSe, afinal, a receber o prêmio da popularidade, entendida no seu legítimo e verdadeiro sentido de compreensão do povo. Mas não pretendo conquistá-la senão com o inalterável cumprimento do dever". 
Deste discurso pode-se concluir que, pela primeira vez na História, o Governo abandonava a Divulgação para adotar o processo da Comunicação e, através dele, obter a participação de todos no esforço de desenvolvimento. E isto pode ser facilmente comprovado pela leitura das primeiras diretrizes traçadas pelo Presidente Médici a seus Ministros de Estado, entre as quais se destaca : "Objetivando informar a opinião pública, motivar a vontade coletiva para o esforço nacional de desenvolvimento e contribuir para o prestígio internacional do Brasil, será estabelecido lim Sistema de Comunicação Social, com base na atuação dos órgãos do Poder Executivo. Princípios de verdade, legitimidade, integração de esforços, eficiência e impessoalidade regerão a comunicação social do Governo. O órgão de direção central do Sistema será a Assessoria Especial de Relações Públicas. Integrar-se-ão ao Sistema os órgãos de Relações Públicas dos Ministérios e do Estado Maior das Forças Armadas, bem como os órgãos similares da Administração Indireta".

Se recordarmos, entretanto, alguns fatos ocorridos no processo de comunicação, durante o Governo passado, facilmente concluiremos que, apesar de todos os esforços desenvolvidos pela AERP, notadamente no sentido da despersonalização da informação e na promoção de grandes campanhas com vistas à consecução dos objetivos traçados pelo Presidente, na prática algumas vezes a teoria foi outra. Se, na cúpula do sistema, a AERP se atirava a patrióticas campanhas em prol do amor à Pátria, da união da família, da produtividade maior, da paz interna, da saúde e da higiene e outras, alguns órgãos que constituiam o Siste$\mathrm{ma}$ - e muitas vezes altas autoridades setoriais - continuaram disputando o espaço nos jornais, confundindo comunicação com propaganda, relações públicas, divulgação e matéria paga.

Torna-se portanto necessário formular-se um Modelo Brasileiro de Comunicação, ou seja, o modo brasileiro de promoverse um constante fluxo de informações entre o Governo e o povo - e vice-versa - a respeito do progresso já alcançado, das novas metas a atingir e, assim, obter a cooperação espontânea $e$ consciente de todos os públicos para uma resposta positiva aos novos desafios que o desenvolvimento thes impõe.

Com esses objetivos é que fomos buscar subsídios em Lucien Pye que destaca três categorias de sociedade - a tradicional, a moderna e a transitória, - "todas elas com muita coisa em comum : suas diferenças são apenas relativas e não absolutas". Analisando-as, uma a uma, verificamos que o Brasil bem se enquadra na sociedade em transição, aquela na qual o processo de 
Comunicação "apresenta uma natureza bifurcada e fragmentada, pois habitualmente envolve, em graus variados, um sistema que se baseia na tecnologia moderna, no predomínio urbano, e alcança os segmentos mais ocidentalizados da população, e também um complexo à parte, que se conforma, em graus variados, com os sistemas tradicionais, por depender das relações face a face e tender a acompanhar os padrões de vida social e comunal. A característica essencial é que os dois niveis e partes separadas não estão intimamente integrados, mas cada qual representa um sistema de comunicação mais ou menos autônomo".

"Na sociedade em transição" - prossegue - "somente de forma errática o processo de comunicação baseado no predomínio urbano penetra nos sistemas à parte, que tem por base as aldeias. Não há, habitualmente, nenhum padrão sistemático de cada rincão isolado, e considerações idiossincrásicas são, com freqüência, decisivas na determinação, em qualquer comunidade, da pessoa que desempenha o papel de transmitir e interpretar as mensagens dos meios de comunicação de massa aos participantes do sistema local. Diferenças no status social e econômico particular dos transmissores de comunidade têm conseqüências decisivas sobre a forma pela qual os diferentes subsistemas se relacionam com o sistema de meios de comunicação de massa. Além dessa divisão fundamental entre o nível urbano e o de elite e o nivel de aldeia, há uma fragmentação em termos de subsistemas isolados. Na verdade, na maioria das sociedades em transição, as aldeias em diferentes partes do País tendem a ter menos comunicação entre si do que têm, separadamente, com Os centros urbaros. O padrão assemelha-se aos raios de uma roda, todos ligados ao eixo, mas sem um aro exterior ou qualquer ligação direta entre si. A maioria dos problemas de desenvolvimento pode ser vista em termos das formas pelas quais esses sistemas de comunicação, fragmentados, podem ser integrados, com mais eficiência, num sistema nacional, embora preservando ainda a integridade dos padrões informais da associação humana. O desenvolvimento traz, implícita, a penetração efetiva do sistema de comunicações de massa em todas as dimensões comunais da nação que vivem isoladas; ao mesmo tempo, os sistemas informais devem desenvolver a capacidade de interagir com o sistema de massa, beneficiando-se do maior fluxo de comunicação, mas mantendo também um senso de comunidade entre seus participantes. O processo de desenvolvimento depende menos do maior investimento no sistema urbanizado, de comunicação de massa, do que do ajuste dos sistemas informais, rurais, entre si, "ao sistema de comunicação de massa". 
Considerando que, de acordo com as características do Estado Brasileiro, o Governo é a principal fonte de informação, vale - sem menosprezar nossos leitores - relembrar o paradigma da Comunicação traçado por Lasswell: quem diz o que, por que canais, a quem, e com que finalidade. Quem diz, podemos imediatamente identificar : o Sistema de Comunicação Governamental. O que : aqui, o problema da mensagem. O desenvolvimento alcançado, os problemas a enfrentar, as novas metas do progresso, tudo com base num plano, que, segundo a Constituição, denominar-se-á II Plano Nacional de Desenvolvimento. A quem : surge ai o problema dos públicos a atingir. Mas, se levarmos em consideração que o objetivo do Governo é mobilizar toda a população capaz de trabalhar para o desenvolvimento, e, além disso, formar na população infantil ou juvenil uma mentalidade favorável ao esforço em prol do progresso, concluiremos que a resposta será : a todo o povo brasileiro. Por que canais : For todos. E aí não se deve cogitar apenas nos jornais, revistas de atualidades, histórias em quadrinhos, rádio, televisão, cinema, disco e fita magnetofônica, que constituem os meios de massa, mas (já que muito mais será exigido das populações rurais) dos instrumentos daquilo que Luís Beltrão denominou folk-comunicação ("o processo de intercâmbio de informação e manifestação de opiniões, idéias e atitudes da massa, através de agentes e meios ligados direta ou indiretamente ao folclore"): os cantadores, os caixeiros-viajantes, os motoristas de caminhão, os folhetos de cordel, os almanaques e folhinhas. Igualmente, dever-se-á utilizar a escola e o livro didático, em todos os níveis, fazendo chegar às mãos de cada estudante e cada professor exemplares do Plano Global de Desenvolvimento, séries estatísticas, a Constituição, planos setoriais, relatórios de órgãos governamentais etc., para que se mantenham atualizados com o desenvolvimento do País. Com que finalidade : para obter uma resposta, não em termos de popularidade ou boa imagem, que constituem conseqüência, mas em termos de participação nos esforços para o progresso.

Agora com Schramm, vale lembrar que, para que tudo funcione bem, será preciso atender sempre a seis condições essenciais :

a) A comunicação deve ser usada na intensificação do sentimento de nação, promovendo a intensificação da fidelidade e da conciência nacional, bem como complementando a fidelidade e consciência local; 
jamento; A comunicação deve ser usada como a voz do plane-

c) A comunicação deve ser usada para ensinar os conhedo efetivo;

d) A comunicação deve ser usada para ampliar o merca-

e) A comunicação deve ajudar a preparar os cidadãos para seus novos papéis, à medida em que o desenvolvimento se processa;

f) A comunicação deve ser usada para preparar o povo Para desempenhar o seu papel de nação entre as nações.

Será preciso, também, o estabelecimento de uma política que, além de atender às seis condições enunciadas, considere a necessidade de não apenas aumentar e acelerar o fluxo de informações, promova a expansão dos meios, sem o que não se poderá enfrentar o principal problema dos anos que se avizinham: o da urbanização.

\section{Uma estratégia para a Comunicação}

Fica-se, agora, com o problema do estabelecimento de uma estratégia que permita realizar ao máximo a comunicação necessária para a total mobilização dos recursos humanos para o desenvolvimento. Tal estratégia, em termos de eficiência, dependerá basicamente de três fatores fundamentais: 1 - Aperfeiçoamento do Sistema de Comunicação Go-
vernamental, principalmente através de:

a) melhoria do status do Assessor de Imprensa, pelo reconhecimento de tratar-se de atividade altamente especializada, Privativa de profissionais devidamente habilitados, e colocada ao nível de consultoria, como porta-voz e conselheiro não apenas da autoridade mais alta, mas de todo o órgão e entidades a ele subordinadas;

de b) real aparelhamento das Assessorias, tanto em termos pessoal como de equipamento;

dina c) verdadeira integração das Assessorias e a sua suborPlação a um órgão central, nos moldes do Sistema Nacional de Gla jamento. Tal órgão encarregar-se-ia de elaborar o Plano Global de Comunicação Governamental, com base em recomendações do Presidente da República e, principalmente no Plano 
Global de Desenvolvimento; da mesma forma, o órgão central encarregar-se-ia da coordenação da execução, de molde a regular o volume de informação e a evitar conflitos entre mensagens;

d) transformação da Agência Nacional numa grande e única - central de informações para os veículos de massa;

e) adoção de pesquisas de comunicação e métodos de constante avaliação pelos órgãos setoriais, que cuidariam, também, de facilitar, de todas as maneiras, o acesso dos veículos de massa às informações, resguardados os aspectos relativos à segurança nacional;

f) criação de um setor específico, voltado para a comunicação rural (folk-comunicação);

g) trabalho em termos de planos setoriais e projetos, $\mathrm{ca}^{-}$ bendo ao órgão central do sistema o estabelecimento de critérios de prioridade para a execução e distribuição dos recursos necessários.

h) integração, a nível nacional, dos órgãos estaduais de comunicação, novamente em paralelo com o que se faz no Ministério do Planejamento e Coordenação Geral.

2 - Integração das fontes de informação governamental com o sistema de veículos de massa, através de:

a) Acesso à informação;

b) Incentivos à expansão da imprensa interiorana, não apenas facilitando-Ihe a aquisição, a preços adequados, de matéria-prima e equipamentos, como na prestação de assistência técnica através do Projeto Rondon e pelo aumento da velocidade na transmissão das mensagens dos grandes centros para as pequenas cidades;

c) Estreitamento das relações com os grandes veículos de massa, urbanizados, através de encontros periódicos para troca de idéias e de experiência.

3 - Desenvolvimento de programas visando ao aproveitamento da comunicação interpessoal para a difusão de novas técnicas e conhecimentos, a fim de obter-se o rápido aperfeiçoa: mento dos recursos humanos, seja nas áreas urbanas, seja nas zonas rurais.

Como vimos, Comunicação para o Desenvolvimento pres" supõe uma política, um plano global compatibilizando planos, pro- 
gramas e projetos setoriais, recursos humanos e financeiros e muita colaboração entre Setor Público e Setor Privado. A fazerSe alguma coisa de outra maneira, será preferivel não fazer nada. Porque, sem estes elementos essenciais, estar-se-á voltando ao triste passado do DIP, da subversão das idéias, dos ideais, das formas e dos fins.

\section{REFEREENCIAS BIBLIOGRÁFICAS}

1 - SCHRAMM, Wilbur - Mass Media and National Development, Stanford University Press, 1964.

2 - SIMONSEN, Mário H. - Brasil 2.002 - APEC Editora, Rio, 1972.

3 - DINES, Alberto - Cadernos de Jornalismo e Comunicação, n. ${ }^{\circ} 9, n{ }^{\circ} 22$ - Edições JB, Rio - 1968/abril e 1970/janeiro.

4 - OLIVEIRA, Luis C. - Cadernos de Jornalismo e Comunicação, n. ${ }^{0} 11$, junho de 1968, Edições JB, Rio.

5 - PINTO, Eduardo - Cadernos de Jornalismo e Comunicação, n. ${ }^{\circ} 23$, março de 1970, Edições JB, Rio.

6 - FRANKLIN, Mário Lúcio - Cadernos de Jornalismo e Comunicação, n. ${ }^{\circ}$ 25, dezembro de 1970, Ediçőes JB, Rio.

7 - FREITAS João B. - Cadernos de Jornalismo e Comunicação, n. ${ }^{\circ} 31$, julho de 1971 - Edições JB, Rio.

8 - guerRA, J. A. - Revista do Serviço Público, Vol. 105, n. ${ }^{\circ} 2$ - maio/ agosto de 1970 - DASP - Brasília.

9 - VIGIANO, Alan - Revista do Serviço Público, Vol. 106, n. ${ }^{\circ}$ 1, janeiro/ abril, 1971 - DASP - Brasilia.

10 - AERP - I Seminário de Relações Públicas do Executivo, 1968, Presidência da República - Brasília.

11 - PYE, Lucien - Comunicações e Desenvolvimento Político - Zahar, Rio, 1967, trad. Luciano Miral.

12 - BELTRÃO, Luis - Comunicação e Folclore - Melhoramentos, São Paulo, 1971. 
